\title{
Prevalence, types, distribution and associations of psychosocial problems among university students in Uganda
}

\author{
Nsereko, Norman David $\bowtie$ \\ Nkumba University, Uganda (nserekon@gmail.com) \\ Musisi, Seggane \\ Makerere University, Uganda (segganemusisi@yahoo.ca) \\ Nakigudde, Janet \\ Makerere University,Uganda (jnakigudde@chs.mak.ac.ug) \\ Holtzman, Steven \\ Center for Data Analysis Research Educational Testing Service, Princeton, New Jersey, USA \\ (sholtzman@ets.org)
}

\begin{tabular}{lll}
$\begin{array}{l}\text { Received: } 19 \text { January } 2014 \\
\text { Available Online: } 17 \text { March 2014 }\end{array}$ & Revised: 23 February 2014 & Accepted: 24 February 2014 \\
\hline
\end{tabular}

\section{Abstract}

The prevalence of psychosocial problems and their associations among University students in Uganda has received very little research attention. Yet, this information is important to provide data to assist in mental health policy formulation for counseling intervention among the vulnerable university students populations in Uganda. The study objective was to investigate the prevalence, types, distribution and associations of psychosocial problems among university students in Uganda. It was part of a larger PhD study that validated an instrument for assessing university students' psychosocial problems in Uganda. This study employed a descriptive cross sectional survey technique. Five universities participated in a survey conducted during the 2012/13 academic year. Out of 1101 approached students, 976 (88.6\%) completed the survey which included a socio-demographic questionnaire, study program characteristics, medical health questionnaire and the University Students Evaluation of Psychosocial Problems (USEPP) instrument which was used to evaluate the psychosocial problems. The prevalence, types and distribution of psychosocial problems among the students was established using descriptive statistics and regression analysis established the relationship between psychosocial problems and the correlates of interest. The estimated prevalence of psychosocial problems among the university students was $36.5 \%$. Students living in off- campus hostels, having chronic medical conditions, and those with a previous history of mental health problems and who perceived their health as poor/fair were at a higher risk of psychosocial problems. These findings highlight to the need to initiate policies to address the students' psychosocial problems.

Keywords: prevalence; psychosocial problems; university students; social demographics; counselling intervention 


\section{Prevalence, types, distribution and associations of psychosocial problems among university students in Uganda}

\section{Introduction}

Psychosocial problems as an aspect of mental health among university students represent an important and growing public health concern for which epidemiological data are needed to inform counseling interventions (Eisenberg, Gollust, Golberstein, \& Hefner, 2007). Psychosocial problems occur in a wide variety of settings and research has shown that they often negatively impact on students' mental health (Ellison, 2004; Ontari \& Angolla, 2008) often leading to maladaptive negative or unhealthy coping mechanisms and compromising student academic performance (Gladding, 2004; Laelia, Apicella, Brakarsh, Dube, Jemison et al., 2006). The resultant mental health problems include emotional, conduct/behavioural, educational and social/interpersonal problems as are often prevalent among adolescents and the youth (Reijneveld, Vogels, Brugman, Van Ede, Verhulst et al., 2003). These problems are of special significance in the students' educational career and their overall mental health (Omokhodion \& Gureje, 2003; Lucas, 1976). They, thus, constitute a growing concern worldwide (Hunt \& Eisenberg, 2010). However, much less is known about the prevalence, severity, distribution and covariate indicators of psychosocial problems among university students in Uganda in order to effectively intervene for the vulnerable students. This aspect has not been established nor systematically investigated in Uganda. Establishing evidence based data of psychosocial problems among university students in Uganda is not only of theoretical importance but may also have implications for devising counselling interventions directed at the most vulnerable students.

\section{Literature Review}

In Western countries, there is a growing body of evidence suggesting that mental health problems are numerous and increasing among students in institutions of higher education worldwide (U.S. Department of Education, National Center for Education Statistics, 2006).

A systematic review of 572 articles by Storrie, Ahern, and Tuckett (2010) that addressed emotional and or mental health problems of university students worldwide indicated that most studies on university students' mental health have concentrated on the internalizing aspects of mental illness with little emphasis on the psychosocial impacts. Stallman (2008) studied psychological distress among university students accessing a university primary care service and found high levels of psychological distress (53\%) in the students, with more than half of students presenting the distress within weeks 6 - 13 of the start of the academic calendar. Similarly, Eisenberg, et al. (2007) examined students for prevalence of major depression, other depression, panic disorder, generalized anxiety disorder and suicidal thoughts. The findings indicated depressive or anxiety disorders with the highest prevalence of $15.6 \%$ among undergraduates and $13.0 \%$ among graduate students who screened as positive for psychological distress.

In Africa, Van Niekerk, Viljoen, Rischbleter, and Scribante (2008) studied the experiences of depressed mood among students at a South African university and found that students had higher rates of depression and suicidal ideation than the general population with $14.9 \%$ of the students being diagnosed with a major depressive disorder compared to the lifetime prevalence of major depressive disorder being between $5 \%-25 \%$ in the general population. In Uganda a study among first year university students in one university indicated that $16.2 \%$ had depressive symptoms, while $24 \%$ of first year medical students reported lifetime experiences of death wishes and 9\% lifetime suicide ideation (Ovuga, Boardman, \& Wasserman, 2006).

These studies on students' psychological distress mainly center on internalizing symptomatology such as stress, depression and anxiety. Nevertheless, they found that these disorders were often under- diagnosed and 
hence under- treated. Sherina, Med, Rampal, and Kaneson (2004) observed that failure to detect these disorders for intervention often led to increased psychological morbidity with unwanted effects throughout the students' academic lives and future careers. None of these studies linked the students' mental illnesses to their psychosocial problems.

One of the few studies on psychosocial problems among Kenyan college and university students by Atwoli, Mungla, Ndung'u, Kinoti, and Ogot (2011) indicated significant physical and psychosocial problems among this population. The prevalence of substance use was high at a rate of $69.8 \%$, alcohol use was $51.9 \%$, cigarette use was $42.8 \%$, cannabis was $2 \%$ and cocaine was $0.6 \%$ leading to high risks of subsequent substance dependence and other deleterious consequences like frequent quarrelling and fights, loss and damage to property, problems with parents, medical problems and unplanned unprotected sex with all its dire consequences (Atwoli et al., 2011). However, little is known about the prevalence of psychosocial problems and their potential demographic risk factors especially in developing countries to influence appropriate interventions among the vulnerable students. These aspects have not been established nor systematically investigated in Uganda. Establishing epidemiological information on university students' psychosocial problems is important to assist in mental health policy formulation for counseling intervention among the vulnerable university student populations in Uganda.

This study aimed to investigate the prevalence, types, distribution and associations of psychosocial problems among university students in Uganda and their correlation to the students' socio-demographic characteristics, study programs and any possible health burdens.

\subsection{Research questions}

What is the prevalence of psychosocial problems among the university students?

What are the severity levels of psychosocial problems among university students?

What is the distribution of symptoms of psychosocial problems among university students?

What are the covariate predictors of psychosocial problems among university students?

\section{Methodology}

\subsection{Study design}

This study was part of a larger PhD study that validated an instrument for assessing university students' psychosocial problems for professional intervention (Nsereko, Musisi, \& Holtzman, 2014). The study employed a descriptive cross sectional survey technique based on quantitative methodology designed to gather basic facts about the prevalence, types and distribution of psychosocial problems among university students and their social demographic correlates.

\subsection{Participants and Recruitment}

A total of 976 out of 1101 randomly selected students from two public and three private universities in Uganda completed the survey instruments, yielding an $88.6 \%$ questionnaire completion rate. One hundred twenty five (11.4\%) of the questionnaires were excluded for providing insufficient/incomplete data for analysis. The age of the participants ranged from 19-49 years with a mean of 23.7 years $(\mathrm{SD}=3.3)$ and $51.6 \%$ were females. The majority of the students were aged $\leq 24$ years $(73.2 \%)$, Ugandan $(93.8 \%)$ single $(87.7 \%)$ and of Christian religious background (76.2\%) with Moslems being $22.2 \%$ and others $1.6 \%$. Most students lived in student accommodation (88.4\%) either in off campus hostels $(57.9 \%)$ or on campus hostels $(30.5 \%)$. In holidays most, $67.2 \%$, lived with their parents, $9.6 \%$ living as married and the rest $(23.3 \%)$ with relatives or alone. The biggest majority of the students $(95.1 \%)$ were involved in fulltime academic day study programs and they were 
supported by their parents $(61 \%)$ or relatives $(20.5 \%)$ who also paid for their education with only $8.9 \%$ being on government or other $(9.6 \%)$ sponsorship. Our participants were mostly in their 2 nd $(42.2 \%)$ or $3^{\text {rd }}(40.9 \%)$ year of study. In terms of their perceived health status, most reported their health as being good or excellent (69.2\%) with $85.2 \%$ stating that they had no chronic medical conditions and $93.4 \%$ expressing having no previous mental health problems.

Inclusion criteria - Only undergraduate students who had completed one semester stay in university were recruited

Exclusion criteria - Postgraduate students and Long Distance Program students

\subsection{Measures}

Socio-demographic variables, study program characteristics and presence of medical illness were selected as the independent variables of study interest. A standardized instrument prepared by the author was used to capture this information. They were divided into three major domains. The student demographic characteristics included, gender, age, religious affiliation, nationality, marital status, parents income level support and whether living with parents or not. The study program characteristics included, university residence location, program of study, years in university and education (fees) sponsorship/funding. The student health-related burden included any chronic medical condition, previous mental health problem and one's perception of their individual health

The Psychosocial problems were assessed using the University Students Evaluation of Psychosocial Problems (USEPP) scale The USEPP has 17 items and it was validated against the Hopkins Symptom Check List (HSCL-10) in non-clinical settings. The scale has an internal consistency of 0.81 as measured by Cronbach's alpha, a sensitivity of $99.3 \%$ and a specificity of $99.6 \%$. The 17-item USEPP measures four dimensions of psychosocial problems which form its subscales. They are Emotional Problems-5 items, Traumatic Experiences4 items, Antisocial Behaviour-5 items and Academic Problems-3 items. Each individual item in the subscale is rated on a scale from 0 (not at all) to 3 (strongly agree). The USEPP is self-administered. An individual is asked to indicate his/her level of agreement with the items that are current concerns to him/her. It has a cut off total score of 18 to indicate compromised psychosocial problem status (Nsereko, et al., 2014). In this study the scale demonstrated internal consistency of 0.82 as measured by Cronbach's alpha. The Traumatic Experiences subscale had .62; the Emotional Problems subscale had .65; the Antisocial Behavior subscale had .75 and the Academic Problems subscale had .60.

\subsection{Procedure}

The study was approved by the Nkumba University Internal Review Board and The Uganda National Council of Science and Technology (UNCST) the National Review Board as well as administrative permissions from the respective university study sites. Data was collected by means self-administered questionnaires during study days free of lecture hours for the five participating universities. Data collection took place during one week in mid-September 2012. It was carried out by the principal researcher and trained research assistants who distributed and collected the questionnaires. In order to ensure maximum turn-over of the responses, the respondents were handed the questionnaires in a single sitting and the questionnaires were collected after the exercise.

At the beginning of each session, the moderators introduced the project to the students in a lecture hall that had been previously arranged for the interview. The purpose of the study and the matters of voluntary consent were communicated to the students before the exercise took off. Those who were not willing to attend to the exercise were free to leave the hall. The students were further explained about the need to carry out the procedure of random selection of participants for recruiting the respondents by recording the members of the class as numbers so that those numbers who were not selected could gracefully accept the outcome of the exercise. These were asked to do their private reading while the selected respondents privately filled the 
Prevalence, types, distribution and associations of psychosocial problems among university students in Uganda questionnaires in confidence without sharing or discussing any information between themselves.

The principal investigator and research assistants distributed the informed consent forms to be voluntarily completed; explained the parameters regarding the study and distributed the survey instruments which included the socio-demographic questionnaire and the University Students Evaluation of Psychosocial Problems (USEPP) questionnaire. The participants and through the consent form, were informed that participation was entirely voluntary and one was free to withdraw from the study at any time. They were then asked to sign the consent form. The participants were encouraged to answer each question honestly, and they were informed that their anonymity was protected as no names were to be written on the completed and returned questionnaires. Compensation for filling out the questionnaire was not provided by the researchers. The research assistants collected the survey instruments upon the completion of the exercise accompanied with a note of thanks to the participants. The completed questionnaires, 976 in all, were then taken and confidentially stored for analysis.

\subsection{Analysis}

Descriptive statistics were calculated to estimate the prevalence of psychosocial problems among university students. Using the USEPP subscales, the type of problems were grouped into the 4 types and their prevalence were calculated. Bivariate analyses were conducted to examine the relationships between covariates of interest and psychosocial problems as the outcome variable. $\mathrm{X}^{2}$ tests were used to identify statistically significant levels taken at p-levels of 0.01. Logistic regression analysis was then performed in order to determine whether or not the factors identified significantly increased the prevalence of psychosocial problems. The contribution of each item to the predictive value of the model was assessed individually and in combination with related items. In order to minimize the likelihood of sample loss due to missing data, separate regression analyses were conducted for each of the three domains of predictor variables, using only those significantly associated (Wald statistic, $\mathrm{P}$ $<.01$ ) with the dependent variable according to the Pearson correlation coefficients. A final logistic regression analysis was performed in order to better determine the relative strength of the predictors and included only those factors significantly related (Wald statistic, $\mathrm{P}<.01$ ) to university students' psychosocial problems in the separate model. This was obtained by using forward selection beginning with student characteristics, followed sequentially by study program characteristics and lastly the student health-burden characteristics.

\section{Results}

\subsection{The prevalence of psychosocial problems among the university students}

Based on the USEPP scores, the prevalence of psychosocial problems among the university students was $36.5 \%$. The mean score was 15.6, SD 9.07. The average age was 24.3 years $(\mathrm{SD}=3.7)$, ranging from 19 to 49 years. For particular problems screened, $34.9 \%$ were positive for emotional problems; $21.4 \%$ for antisocial behavior; $48.9 \%$ for trauma experiences and $37.8 \%$ for academic problems. The prevalence of psychosocial problems was slightly higher among the females $(51.3 \%)$ compared to the males $(48.7 \%)$. The age group of $\leq 24$ years experienced more psychosocial problems $(66.6 \%)$ than all the remaining age groups put together. The Catholics had more psychosocial problems of all the religious groups and being single indicated higher scores of psychosocial problems. The analysis of psychosocial problems with gender and marital status showed statistical significance at $\mathrm{p}<0.05$ while age, religious affiliation and nationality was at $\mathrm{p}<0.01$ (Table 1 ).

\subsection{Severity levels}

On the USEPP total scale, range obtained in the scoring system was calculated and divided into three levels of psychosocial problems: mild, moderate and severe. $63.5 \%$ students had mild psychosocial problems, $30.8 \%$ had moderate psychosocial problems and 5.7\% had severe levels of psychosocial problems. On the different subscales, $65 \%$ on the emotional sub scale had mild levels while, $32.5 \%$, were moderate and $2.5 \%$ were severe. On the antisocial subscale, $78.5 \%$ had mild problems, $19.6 \%$ were moderate and $1.9 \%$ was severe. On the trauma 
Nsereko, N. D., Musisi, S., Nakigudde, J., \& Holtzman, S.

subscale, $51 \%$ had mild problems, $46.6 \%$ were moderate and $2.4 \%$ were severe. On the academic subscale, $62.2 \%$ had mild problems, $36.6 \%$ were moderate and $1.2 \%$ were severe.

\section{Table 1}

Association of psychosocial problems with Gender, Age, Religious Affiliation, Nationality and Marital Status among the Respondents ( $N=976)$

\begin{tabular}{|c|c|c|c|}
\hline Associated factor & $\begin{array}{c}\text { Students without } \\
\text { psychosocial problems } \\
(\mathrm{n}=620)\end{array}$ & $\begin{array}{l}\text { Students with psychosocial } \\
\text { problems }(\mathrm{n}=356)\end{array}$ & $p$ value \\
\hline Gender & & & $* p<0.05$ \\
\hline Male & $302(48.7 \%)$ & $170(47.8 \%)$ & \\
\hline Female & $318(51.3 \%)$ & $186(52.2 \%)$ & \\
\hline Total & $620(63.5 \%)$ & $356(36.5 \%)$ & \\
\hline Age & & & $* * p<0.01$ \\
\hline$\leq 24$ & $477(76.2 \%)$ & $237(66.6 \%)$ & \\
\hline $25-29$ & $124(20 \%)$ & $84(23.6 \%)$ & \\
\hline $30-34$ & $7(1.1 \%)$ & $27(7.6 \%)$ & \\
\hline $35-39$ & $9(1.5 \%)$ & $7(2.0 \%)$ & \\
\hline$\geq 40$ & $3(0.5 \%)$ & $1(0.3 \%)$ & \\
\hline Religious affiliation & & & $* * p<0.01$ \\
\hline Moslem & $130(21 \%)$ & $87(24.4 \%)$ & \\
\hline Church of Uganda & $180(29 \%)$ & $92(25.8 \%)$ & \\
\hline Catholic & $170(27.4 \%)$ & $111(31.2 \%)$ & \\
\hline Born again & $128(20.6 \%)$ & $62(17.4 \%)$ & \\
\hline Other & $12(1.9 \%)$ & $4(1.1 \%)$ & \\
\hline Nationality & & & $* * p<0.01$ \\
\hline Ugandan & $587(94.7 \%)$ & $329(92.4 \%)$ & \\
\hline Other & $33(5.3 \%)$ & $27(7.6 \%)$ & \\
\hline Marital status & & & $* p<0.05$ \\
\hline Single & $561(90.5 \%)$ & $295(82.96 \%)$ & \\
\hline Married & $43(6.9 \%)$ & $51(14.3 \%)$ & \\
\hline Other & $16(2.6 \%)$ & $10(2.8 \%)$ & \\
\hline
\end{tabular}

Table 2

Symptoms of psychosocial problems among the student participants ( $n=976)$

\begin{tabular}{|c|c|c|c|}
\hline Symptom & $n(\%)$ & Mean & $S D$ \\
\hline \multicolumn{4}{|l|}{ Emotional Problems } \\
\hline Feeling stressed, being in low mood & $766(78.5)$ & 1.42 & 1.01 \\
\hline I sometimes find it difficult to sleep or I sleep too much & $637(65.3)$ & 1.24 & 1.10 \\
\hline I have problems of concentrating in life generally & $572(58.6)$ & 1.30 & 1.05 \\
\hline Experiences of irrational fears/phobia & $559(57.3)$ & 1.00 & 1.05 \\
\hline Sometimes experiencing wishes of being dead & $357(36.6)$ & 0.67 & 1.00 \\
\hline \multicolumn{4}{|l|}{ Antisocial Behavior } \\
\hline I am involved in behaviors I should be ashamed of if they became public & $327(33.5)$ & 0.65 & 1.03 \\
\hline Gambling/betting for financial gain & $281(28.8)$ & 0.57 & 0.99 \\
\hline I take sexual advantage of others & $236(25.8)$ & 0.50 & 0.96 \\
\hline Uncontrolled drinking of alcohol & $204(20.9)$ & 0.41 & 0.89 \\
\hline Involved in one way or the other in academic mal practice & $195(20)$ & 0.42 & 0.90 \\
\hline \multicolumn{4}{|l|}{ Traumatic Experiences } \\
\hline Often lacking welfare/pocket money for personal use & $689(70.6)$ & 1.3 & 1.11 \\
\hline Adjustment problems in my new environment i.e. hostel, campus life & $595(61)$ & 1.04 & 1.01 \\
\hline My family is experiencing problems of which I am of great concern & $553(56.7)$ & 1.12 & 1.17 \\
\hline Unpredictable/Insecure tuition fees status & $553(56.7)$ & 1.10 & 1.14 \\
\hline \multicolumn{4}{|l|}{ Academic Problems } \\
\hline I am not able to concentrate on my studies as I would have liked & $631(64.7)$ & 1.15 & 1.08 \\
\hline Inadequate study skills to meet university academic demands & $572(58.6)$ & 1.06 & 1.08 \\
\hline Low academic grades & $530(54.3)$ & 0.83 & 0.93 \\
\hline
\end{tabular}

\subsection{Prevalence of Symptoms of Psychosocial Problems}

Eleven of the symptoms of psychosocial problems were each experienced by more than $50 \%$ of the student 
respondents while only six symptoms were each experienced by less than $40 \%$ of the respondents. On the emotional subscale the majority of the students were stressed, being in low mood while sometimes experiencing wishes of being dead had the least percentage of score. On the antisocial behavior subscale, most of the symptoms were experienced by less than a third of the respondents while being involved in behaviors I should be ashamed of if they became public was the highest experienced symptom. On the traumatic subscale, often lacking welfare/pocket money for personal use and my family is experiencing problems of which I am of great concern were the symptoms highly affecting the students. The academic problems subscale indicated that more than $54 \%$ of the respondents experienced each of the three symptoms with I am not able to concentrate on my studies as I would have liked being the greatest symptom recorded. Table 2 summarizes these symptoms in four subscales.

\subsection{The correlates of psychosocial problems}

Bivariate analyses for identifying significant covariates of psychosocial problems - As shown in Table 3, ten of the independent variables were significantly $(p<0.01)$ correlated with the outcome variable (dependent variable), psychosocial problems, which were assessed using the USEPP.

Table 3

Bivariate Analyses between Covariates of Interest and Psychosocial Problems

\begin{tabular}{llll}
\hline Variable & $R$ & Mean & $S D$ \\
\hline Students' demographic characteristics & & & .50 \\
Gender & -.11 & 1.5 & 1.07 \\
Age & $.29^{* *}$ & 2.4 & .28 \\
Religious affiliation & $-.27^{* *}$ & .01 & .28 \\
Nationality & $-.15^{* *}$ & .01 & .47 \\
Marital status & .13 & 1.2 & .63 \\
\hline Students' program characteristics & & & .28 \\
University residence location & $-.26^{* *}$ & 1.7 & .63 \\
Program of study & $.14^{* *}$ & 1.08 & .48 \\
Years in University & $-.26^{* *}$ & 1.65 & .89 \\
Living with parents & -.01 & 1.39 & .42 \\
Education sponsorship & .09 & 1.76 & .83 \\
\hline Student burden related characteristics & & & .32 \\
Chronic medical condition & $-.24^{* *}$ & 1.76 & \\
Previous mental health condition & $-.27^{* *}$ & 2.58 & \\
Perception of health & $-.35^{* *}$ & 1.88 & \\
\hline Note $* * * p<01$ & & &
\end{tabular}

The Odds of Experiencing Psychosocial Symptoms - Logistic regression analysis was first performed to identify the models that demonstrated a good fit to the data. As indicated by the significant model $\chi^{2}$ values, all the three models predicting psychosocial problems were statistically significant demonstrating a good fit to the data (Table 4). Next a logistic regression analysis was then performed in order to determine whether or not the factors identified in the bivariate analysis $(p<0.01)$ significantly increased the likelihood of psychosocial problems, with separate models for three types of risk factors. The reference groups for dummy-coded variables were as follows: for age, $\leq 24$, for university residence location, off-campus hostel, for program of study, day, for chronic medical condition, none, for previous mental health problem, none and for perception of health, poor/fair. The unstandardized coefficients (B), standardized error (SE) odds ratios EXP (B), significance (p) and Walid confidence limits for each model are presented in Table 4. However, the proportion of variance explained indicates that student program characteristics were best able to predict the prevalence of psychosocial problems, followed by student burden characteristics, and student demographic characteristics.

As shown in Model 1 age was the only variable that contributed significantly although very weakly associated with predicting psychosocial problems among the student demographic characteristics. There was a decrease by a factor of 0.70 by every age group, $p=.000$ from the age of $\leq 24$ in predicting psychosocial problems. This meant that being at the age group above $\leq 24$ was $30 \%$ less likely to experience psychosocial problems. The results further indicated that gender or nationality were not significant predictors of psychosocial problems 
Nsereko, N. D., Musisi, S., Nakigudde, J., \& Holtzman, S.

among university students.

Table 4

Multinomial Logistic Regression Predicting Psychosocial Problems among University Students

\begin{tabular}{|c|c|c|c|c|c|c|}
\hline Variable & $B$ & $S E$ & $\mathrm{EXP}(\mathrm{B})$ & $95 \% \mathrm{CI}$ & $P$ & $R^{2}$ \\
\hline $\begin{array}{l}\text { Module 1: } \\
\text { Students'demographic characte }\end{array}$ & & & & & & .02 \\
\hline Age & -.350 & .097 & .704 & $0.58-0.85$ & .000 & \\
\hline Religious affiliation & .073 & .062 & 1.076 & $0.95-1.22$ & .234 & \\
\hline Nationality & -.286 & .264 & .751 & $0.45-1.26$ & .278 & \\
\hline \multicolumn{7}{|l|}{ Module 2: } \\
\hline Study program Characteristics ${ }^{\mathrm{b}}$ & & & & & & .15 \\
\hline University residence location & .612 & .116 & 1.845 & $1.85-1.47$ & .000 & \\
\hline Program of study & -.625 & .328 & .535 & $0.54-0.28$ & .057 & \\
\hline Years in University & .109 & .093 & 1.115 & $1.12-0.93$ & .242 & \\
\hline Income of parents & -.807 & .108 & .446 & $0.45-0.36$ & .000 & \\
\hline Module 3 & & & & & & .12 \\
\hline \multicolumn{7}{|c|}{ Student burden related characterists ${ }^{c}$} \\
\hline Chronic medical condition & 610 & .199 & 1.841 & $1.25-2.72$ & .002 & \\
\hline Previous mental health problem & .819 & .296 & 2.268 & $1.27-4.06$ & .006 & \\
\hline Perception of health & 649 & .097 & 1.914 & $1.58-2.31$ & .000 & \\
\hline
\end{tabular}

In model 2, university residence location where the student resides during study time, study program and parents' level of income to support the student were significant predictors of psychosocial problems. University residence location was moderately increased by a factor of $1.85, p=0.000$ to having psychosocial problems. This means that students who stayed in hostels outside the university premises had 3 times (85\%) more odds of having psychosocial problems than those who lived in university halls of residence or attended university studies from other locations. According to study program there was a very weak relationship with the presence of psychosocial problems. It showed a decreased presence of psychosocial problems among students who attended weekend study program compared to those who attended day program. The weekend students were $46 \%$ less likely (decreased by a factor of $.54, p=.06$ ) to have psychosocial problems. Students whose parents could support them comfortably at university or those who were able but with some difficulties were $55 \%$ less likely per level ability (decreased by a factor of .45, $p=.000$ ) to have psychosocial problems than those students whose parents were unable to support them at all. The students' year of study did not significantly contribute to the presence of psychosocial problems.

In model 3, all the three student- burden related factors were moderately associated with psychosocial problems. Those who reported presence of a chronic medical condition had $84 \%$ the odds of having a psychosocial problem $(1.841, p=.002$ (CI, 95\%, $1.24-2.72)$ than those who did not have the condition. Those who reported presence of a mental health condition before had $27 \%$ the odds of having a psychosocial problem (2.268, $p=.006$ (CI, 95\%, 1.27-4.06) than those who did not have the condition. Those who perceived their health as poor/fair had $91 \%$ the odds of having a psychosocial problem $(1.914, p=.000,(\mathrm{CI}, 95 \%, 1.58-2.31)$ than those who indicated good/excellent.

A final logistic regression analysis was performed which included all significant predictors $(p<0.01)$ listed in Table 4. The parameter estimates for the final model are shown in Table 5:15. Adjusted odds ratio with 95\% confidence interval was used to determine the risk factors for psychosocial problems. Student burden characteristics and to some extent student program characteristics demonstrated a moderate association with psychosocial problems than the student demographic characteristic which had a weak association. There was more risk for psychosocial problems among university students who perceived their health as poor/fair (increased by a factor of 1.68 compared to those who perceived as it as good/excellent $p=.000$ ); those who stayed at off campus hostel (increased by a factor of 1.71, compared to those who stayed on-campus hostels, $p=.000$ ); those who had a chronic medical condition (increased by a factor of 1.84 , compared to those who had none, 

$\mathrm{p}=.003$ ); and those who had a mental health problem before (increased by a factor of 2.0 compared to those who indicated they had none, $\mathrm{p}=.03$ ). Age, and the income level of parents to support a student at university students, program of study showed decreased factors in the likelihood to having psychosocial problems from the group expected to have higher odds of psychosocial problems. Being older (decreased by a factor of 0.83 for each year increase in age, $\mathrm{p}=.08$ ) was less likely to be associated with psychosocial problems. Having parents who could financially support a student at university was less likely to be associated with psychosocial problems (decreased by a factor of 0.52 ) compared with those whose parents were unable to support them. $\mathrm{P}=.000$. Weekend program was also less likely to be associated with psychosocial problems (decreased by a factor of .52 compared with day program of study, $\mathrm{p}=.06$ ).

Overall, the significant model $\chi 2$ value (Table 5) indicated a good fit to the data, with relationships of mild to moderate predictive power. The regression equation, while statistically highly significant $(\mathrm{P}=0.000)$, accounted for a modest amount of variance (0.22), suggesting that there is still much to uncover about the correlates and predictors of the prevalence of psychosocial problems among university students such that other variables may have been better able to predict the prevalence of psychosocial problems among university students. The explanatory power of such models could be enhanced through the inclusion of additional predictor variables and examination of the interaction between particular predictor variables (e.g. emotional problems, trauma experiences, antisocial behavior and academic problems) in addition to the analysis of their simple overall effects.

\section{Table 5}

Final model: Multinomial Logistic Regression Predicting Psychosocial Problems among University Students

\begin{tabular}{lccrrrr}
\hline Model & $B$ & SE & EXP(B) & $95 \%$ CI & $P$ & $R^{2}$ \\
\hline Final Model $^{\mathrm{a}}$ & & & & & & .22 \\
Age & -.187 & .107 & .829 & $.67-1.02$ & .08 & \\
University residence location & .537 & .120 & 1.710 & $1.35-.17$ & .000 & .06 \\
Program of study & -.653 & .348 & .520 & $.26-.03$ & .06 & .000 \\
Income of parents & -.663 & .114 & .515 & $.41-.65$ & .003 \\
Chronic medical condition & .609 & .208 & 1.840 & $1.22-.76$ & .006 \\
Previous mental health problem & .693 & .314 & 2.268 & $1.08-.70$ & .000 \\
Perception of health & .517 & .102 & 1.914 & $1.37-.05$ & \\
\hline
\end{tabular}

Note. $(\mathrm{B})=$ The unstandardized coefficients, $\mathrm{SE}=$ standardized error, $\mathrm{EXP}(\mathrm{B})=$ odds ratios, $\mathrm{CI}=$ confidence interval, $\mathrm{p}=$ significance, $\mathrm{r}^{2}=$ proportion of variance explained, ${ }^{a}$ Data for psychosocial problems, $\mathrm{N}=356, \mathrm{X}^{2}=168.61, \mathrm{p}=.000$

\section{Discussions}

\subsection{Prevalence Rates of Psychosocial Problems}

This study provides preliminary data highlighting the prevalence of psychosocial problems in university students in Uganda. More than a third (36.5\%) of the university student respondents reported having psychosocial problems ever since they entered university. This figure represented a group of the students presenting experiencing moderate to severe levels of psychosocial problems. On individual subscales the prevalence was indicated as emotional problems (34.9\%); antisocial behavior (21.4\%); trauma experiences $(48.9 \%)$ and academic problems $(37.8 \%)$. Previous research indicated that students who had psychosocial problems were significantly associated with psychological distress in a form of depression and anxiety (Nsereko, Musisi, Nakigudde, \& Ssekiwu, 2014). These findings therefore suggest that the prevalence of psychosocial problems as well as mental illness is significant among students on Ugandan university campuses.

Consistent with previous published studies on mental health among students, it was indicated that the number of students with mental health problems was high and that the severity of their problems was also high. For instance recent research in the UK indicates that mental health or psychological problems within student populations were as high as $40 \%$, with most students suffering from depression or anxiety, or both (Sherina et al., 2004). These findings therefore suggest that the prevalence of psychosocial problems are significant and they are 
indeed a basis for concern among students on Ugandan university campuses. The apparent high levels of psychosocial problems identified by the study could possibly suggest that current structures provided by universities to support students, may not be keeping pace with the changing world.

On gender, $47.8 \%$ of the male respondents and $52.2 \%$ females reported having psychosocial problems. These findings are consistent with other previously published studies on student mental health indicating female students with higher vulnerability than male students (Hyun, Quinn, Madon, \& Lustig, 2006; Sherina, et al., 2004, Ahmad, Khalique, Khan, \& Amir, 2007) and in the general population (Center for Disease Control and Prevention, 2004). On age, the findings indicated that the majority of university students to experience mental health difficulties were in the age bracket of $\leq 24$ years. This is consistent with previous research that found that higher mental health illness prevalence was in the late adolescent and early adult stages of development (Wittchen, Nelson, \& Lachner, 1998; Michuad \& Fombonne, 2005; Harper \& Peterson, 2005; Kitzrow, 2003; Landstedt, 2010; Ahmad et al., 2007).

\subsection{The Correlates of Psychosocial Problems}

Overall, this study found that psychosocial problems among university students were predicted by all the three domains of social demographic variables, including student demographic characteristics (age); student study program characteristics (university residence location, program of study, income level of parents) and student-related burden characteristics (chronic medical condition, mental health problem, perception of health). As shown in the final model, chronic medical condition, mental health problem, perception of health and university residence location during study time more than tripled the likelihood of students having psychosocial problems. Similar findings of student related burden characteristics to influence student mental health have been reported in previous studies in many countries (Pledge, Lapan, Heppner, Roehlke et al., 1998; Reijneveld et al., 2003; Laelia et al., 2006; Harper \& Peterson, 2005; Nsereko et al., 2014) and there appears to be general agreement in the literature that one of the strongest predictors of psychosocial problems among students are associated with student-related burden characteristics.

On age it was found out that the younger the age the more likelihood to experience psychosocial problems. This finding corroborates with earlier studies on university students visiting counselling centers that found younger students with more severe diagnoses than older on psychological distress (Kettmann, Schoen, Moel, Cochran, Greenberg et al., 2007). Our results also suggest that students living in off- campus hostels were 3 times more likely to have psychosocial problems than those living in a campus dormitory. This finding corroborates with one study that indicated that students living on university campus residence was associated with significantly lower risks of mental health problems (Eisenberg et al., 2007). It may be suggested that these residences do not offer similar on campus kind of arrangements to mediate the challenges associated with university adjustment issues involving important decisions related to student roles. A student finds himself/herself struggling to adapt to both university and off-campus hostel settings. The latter may sometimes fail to offer supportive, constructive and positive interactions with university staff and other students suggesting a crisis in stress levels due to changes in attachment patterns (Bowlby, 1973; Eisenberg et al., 2007). A student might easily be influenced by the liberal off-campus atmosphere to take options that can compromise his/her study career with dire consequences to emotional problems, antisocial behavior, traumatic experiences and academic problems. Given that $78.7 \%$ of university students face unpredictable support at university, off-campus hostile environment may pose more stiff challenges. A student has to fend for himself in terms of student welfare e.g. securing daily meals, medical attention, and stand by himself/herself in important decisions of life from influences within and from without, footing to attend lectures or even being liable to personal/property insecurity incidents leading a student to constant stress and uncertainties.

The negative finding of gender disparity as a significant risk factor to psychosocial problems in this study is inconsistent with the majority of published literature in this area (Druss, Marcus, Rosenheck, Olfson, Tanielian et al., 2000; Malinckrodt \& Leong, 1992; McLaughlin, 1985; Silverman, Meyer, Sloane, Raffel, Pratt et al., 1997; 
Sherina et al., 2004; Hyun et al., 2006). A number of possible explanations can be given. The majority studies on mental health vulnerability have concentrated on internalizing factors like depressions and anxiety (Stallman 2008; Eisenberg et al., 2007, Ghandour, Kogan, Blumberg, \& Perry, 2010) finding female gender as a significant risk factor to the development of mental illness.

This study examined psychosocial problems which included both internalizing and externalizing factors i.e. emotional difficulties, trauma experiences, antisocial behavior and academic problems. The externalizing factors e.g. academic difficulties, trauma experiences and antisocial behaviour in this regard may not necessarily be a preserve of any gender. Both males and females university students might be facing similar stressors, which may explain the lack of gender difference observed in as risk factor. For instance Nath, Paris, Thombs and Kirmayer (2012) have noted that the changing gender roles may present stressors similar to those that affect males in relation to educational choices, job opportunities and financial responsibility for their families. Religious affiliation or religiosity and/ or spirituality variable need to be discussed as surprise result although it was not at the cut off significance level at p. $<0.01$ to be included in the logistic analysis. In the bivariate analysis it was significantly related to psychosocial problems $(\mathrm{p} .<0.05)$ and more than $98 \%$ of the students indicated affiliation to a religious group.

Research has shown that religion/spirituality is a significant component of an individual's life (Pickard \& Tang, 2009) whereby it can encourage personal empowerment, that affirm and embrace diversity and that promote the importance of emotions such as hope, forgiveness and purpose. On the other hand some aspects of spirituality seem to have no effect on mental health or, in some cases, can lead to feelings of guilt, shame or powerlessness, which can be damaging or harmful to a person's mental health (Cornah, 2006). Anecdotal, quantitative and qualitative evidence across a range of disciplines including psychology, psychiatry, theology, nursing and gerontology, acknowledge that spirituality serves as part of an integrative approach to understanding mental health and wellbeing and that it makes a positive contribution to mental health (Cornah, 2006).

Spiritual traditions common to most religions, including liturgy, worship and prayer, church/temple/mosque attendance and belief in a transcendent being have been positively associated with reduced depressive symptoms amongst adults, children and young people. Other studies that examined a link between religion, spirituality, and trauma-based mental health problems have indicated that traumatic experiences led to a deepening of religion or spirituality and that positive religious coping, religious openness, readiness to face existential questions, religious participation, and intrinsic religiousness were typically associated with improved post-traumatic recovery (Swinton, 2001; Cornah, 2006; Renu \& Manju, 2013).

The strength of these data is the availability of unique information on the prevalence of psychosocial problems among a large representative sample of university student population and a variety of covariates, which allowed the students at risk for psychosocial problems to be evaluated. Whilst the findings obtained in this study are not based on clinical diagnostic instruments, the researchers believe that the data is indicative of serious issues that warrant further investigation. Considering that there are no available reported statistics on prevalence of psychosocial problems among a representative university sample, we believe that the estimates of this study represent a fair liberal, foundation to support organizational initiatives to improve the mental health status of university students in Uganda. Bivariate analysis showed that significant proportions of demographic variables were associated with student psychosocial problems. After controlling for significant covariates, however, only 4 of the 14 conditions were associated with greater odds of having psychosocial problems while 3 were associated with decreased occurrence of psychosocial problems.

\section{Conclusion}

In summary, this study highlights the prevalence, types, distribution and associations of psychosocial problems among university students in Uganda and their risk factors among social demographic covariates. Psychosocial problems are a significant phenomenon affecting $36.5 \%$ of the total university students. 
Specifically, emotional, academic, antisocial behavior problems and traumatic experiences were predominant among the students. Four covariates namely students living in off- campus hostels, having a chronic medical condition, previously with a mental health problem and who perceived their health as poor/fair were at a higher risk of psychosocial problems. It suggests important directions for policy formulation and future research that explore equitable approaches to address psychosocial problems on university campuses in Uganda.

\subsection{Limitations}

The study lacked comparable measures of psychosocial problems from the national health survey statistics in order to better estimate the university students prevalence levels and the nature of covariates to psychosocial problems among this age group and the existing planning efforts to tackle the problems. It is therefore unclear whether the estimates of students' psychosocial problems are overestimates or underestimates of the true population need. The students who were already consumers of mental health services were not specifically targeted leading to sampling bias in which those with greater need were underrepresented. The study relied on self-reported measures of student burden characteristics whose responses might have been socially induced. There was also response bias based on lack of adequate representation of respondents from the science oriented courses due to the fact that majority of the study sites offer predominately arts courses. The results should be interpreted with caution since these limitations may affect their generalization.

\subsection{Implications for Prevention, Service Delivery, and Policy}

The findings of the study highlight the importance of university administrators and other service providers working, within a university, to be aware that many students presenting with psychosocial problems may also be experiencing mental health problems. This calls for the provision of timely intervention measures by each university to address the phenomena of student psychosocial problems. General Practitioners, psychiatrists and clinical psychologists should be involved to promote a team approach in intervention programs to increase the availability of care for students with mental health problems.

University administrators should come up with a mental health policy to address students' over all mental health problems. They should also consider making it a requirement for a lecture post, one to have undertaken mental health literacy skills training. This would enable the lecturers to easily identify vulnerable students and effect referrals to competent mental health service staff. Basing on the findings of the propensity of student vulnerability to psychosocial problems at off campus hostels, university administrators should initiate cooperative efforts with off-campus hostel proprietors to include among their hostel personnel counsellors to attend to the students in need of counselling services.

Given the fact that the majority of the students belonged to any particular religious affiliation, faith based services to students should be an integral part of university team to address the students' psychosocial problems. Mental health professionals through public-private partnerships may assist clergy in identifying problems and making appropriate referrals (Pickard \& Tang, 2009).

\subsection{Direction for Future Research}

More research is needed to investigate how vulnerable students utilize mental health services. Since there is also a growing number of post graduate students in Uganda universities it would be an important study to find out the risk factors to psychosocial problems among this group of students. There is need to carry out processes and outcome studies of university counselling centers and GP settings to ascertain whether the quality of mental health care given to students is equitable.

\section{References:}


Prevalence, types, distribution and associations of psychosocial problems among university students in Uganda

Ahmad, A., Khalique, N., Khan, Z., \& Amir, A. (2007). Prevalence of psychosocial problems among school going male adolescents. Indian Journal of Community Medicine, 32, 219-221. http://dx.doi.org/10.4103/0970-0218.36836

Atwoli, L., Mungla, P. A., Ndung'u, M. N., Kinoti, K. C., \& Ogot, E. M. (2011). Prevalence of substance use among college students in Eldoret, western Kenya. Retrieved June 20, 2012, from http://www.biomedcentral.com/1471-244X/11/34

Bowlby, J. (1973). Attachment and loss: Separation anxiety and anger. London: Hogarth Press.

Center for Disease Control and Prevention. (2004). Self-reported frequent mental distress among adults-United States, 1993-2001. MMWR, 53, 963-966.

Cornah, D. (2006). The impact of spirituality upon mental health: A review of the literature. Retrieved February 8, 2012, from http://socialwelfare.bl.uk/subject-areas/services-client-groups/adults-mental-health/mentalhealthfoundat ion/1526282006_impact_spirituality.pdf

Druss, B. G., Marcus, S. C., Rosenheck, R. A., Olfson, M., Tanielian, T., \& Pincus, H. A. (2000). Understanding disability in mental and general medical conditions. American Journal of Psychiatry, 157, 1485-1491. http://dx.doi.org/10.1176/appi.ajp.157.9.1485

Eisenberg, D., Gollust, S. E., Golberstein, E., \& Hefner, J. L. (2007). Prevalence and Correlates of Depression, Anxiety, and Suicidality among University Students. American Journal of Orthopsychiatry, 77(4), 534-542. http://dx.doi.org/10.1037/0002-9432.77.4.534

Ellison, K. W. (2004). Stress and the police officer. (2nd ed.), Springfield, IL: Charles C. Thomas Publishers.

Ghandour, R. M., Kogan, M. D., Blumberg S. J., \& Perry, D. F. (2010). Prevalence and correlates of internalizing mental health symptoms among CSHCN. Pediatrics, 125(2), 269-277. http://dx.doi.org/10.1542/peds.2009-0622

Gladding, S. T. (2004). Counseling: A compressive profession. (5th ed). Ohio: Pearson, Merrill Prentice Hall.

Harper, R., \& Peterson, M. (2005). Mental health issues and college students. NACADA Clearinghouse of Academic Advising Resources. Retrieved January 10, 2011, from http://www.nacada.ksu.edu/clearinghouse/advisingissues/mental-health.htm

Hunt, J. \& Eisenberg, D. (2010). Mental health problems and help-seeking behavior among college students. Journal of Adolescent Health, 46, 3-10. http://dx.doi.org/10.1016/j.jadohealth.2009.08.008

Hyun, J. K., Quinn, B. C., Madon, T., \& Lustig, S. (2006). Graduate student mental health: Needs assessment and utilization of counseling service. Journal of Student College Development. 47(3), 247-266. http://dx.doi.org/10.1353/csd.2006.0030

Kettmann, J. J. D., Schoen, E. G., Moel, J. E., Cochran, S. V., Greenberg, S. T., \& Corkery, J. M. (2007). Increasing severity of psychopathology at counseling centers: A new look. Professional Psychology: Research and Practice, 38(5), 523-529. http://dx.doi.org/10.1037/0735-7028.38.5.523

Kitzrow, M. A. (2003). The mental health needs of today's college students: Challenges and recommendations. Retrieved June 20, 2012, from depts.washington.edu/apac/roundtable/1-23-07_mental_health_needs.pdf

Laelia, G., Apicella, L., Brakarsh, J., Dube, L., Jemison, K., Kluckow, M., Smith, T., \& Snider, L. (2006). Orphans and vulnerable youth in Bulawayo, Zimbabwe: An exploratory study of psychosocial well-being and psychosocial support. Retrieved June 18, 2012, from www.popcouncil.org/pdfs/horizons/zimorphans.pdf

Landstedt, E. (2010). Life circumstances and adolescent mental health: Perceptions, associations and a gender analysis. Unpublished doctoral thesis, Mid Sweden University, Stockholm.

Lucas, C. J. (1976). Aspects of Student Health Psychological problems of students. British Medical Journal, 2 , 1431-1433. http://dx.doi.org/10.1136/bmj.2.6049.1431

Malinckrodt, B., \& Leong, F. (1992). Social support in academic programs and family environments: Sex differences and role conflicts for graduate students. Journal of Counseling \& Development, 70, 716-723. http://dx.doi.org/10.1002/j.1556-6676.1992.tb02154.x

McLaughlin, M. (1985). Graduate schools and families: Issues for academic departments and university mental health professions. Journal of College Student Personnel, 26, 488-491. 
Nsereko, N. D., Musisi, S., Nakigudde, J., \& Holtzman, S.

Michaud, P. A., \& Fombonne, E. (2005). Common mental health problems. British Medical Journal, 330, 835-838. http://dx.doi.org/10.1136/bmj.330.7495.835

Nath, Y., Paris, J., Thombs, B. \& Kirmayer, L. (2012). Prevalence and social determinants of suicidal behaviours among college youth in India. International Journal of Social Psychiatry 58(4), 393-399.

http://dx.doi.org/10.1177/0020764011401164

Nsereko, N., Musisi, S., \& Holtzman, S. (2014). Evaluation of psychosocial problems among African university students in Uganda: Development and validation of a screening instrument. Psychology Research, 2(4), 112-131.

Nsereko, N., Musisi, S., Nakigudde, J., \& Ssekiwu, D. (2014). Psychosocial problems and development of psychopathology among Ugandan university students. International Journal of Research Studies in Psychology. http://dx.doi.org/10.5861/ijrsp.2014.638

Omokhodion, F., \& Gureje, O. (2003). Psychosocial problems of clinical students in the University of Ibadan. African Journal of Medicine and Medical Sciences, 32(1), 55-68.

Ontari, H., \& Angolla, J. E. (2008). Occupational stress in organizations and its effects on organizational performance. Journal of Management. Research, 8(3), 123-135.

Ovuga, E., Boardman, J., \& Wasserman, D. (2006) Undergraduate student mental health at Makerere University, Uganda. World Psychiatry, 5(1), 51-52.

Pickard, J. G., \& Tang, F. Y. (2009). Older adults seeking mental health counseling in a NORC. Research on Aging, 31(6), 638-660. http://dx.doi.org/10.1177/0164027509343539

Pledge, D., Lapan, R., Heppner, P., \& Roehlke, H. (1998). Stability and severity of presenting problems at a university counselling center: A 6-year analysis. Professional Psychology Research and Practice, 24(4), 386-389. http://dx.doi.org/10.1037/0735-7028.29.4.386

Reijneveld, S. A., Vogels, A. G. C., Brugman, E., Van Ede, J., Verhulst, F. C., \& Verloove-Vanhorick, S. P. (2003). Early detection of psychosocial problems in adolescent. How useful is the Dutch short indicative questionnaire (KIVPA)? European Journal of Public Health, 13, 152-159. http://dx.doi.org/10.1093/eurpub/13.2.152

Renu, S., \& Manju, D. (2013). Spiritually and mental health among normal and chronic disease group. International Journal of Research Studies in Psychology, 2(1), 59-68.

Sherina, M. S., Med, M., Rampal, L., \& Kaneson, N. (2004). Psychological Stress among Undergraduate Medical Students. Medical Journal Malaysia, 59(2), 207-211.

Silverman, M. M., Meyer, P. M., Sloane, F., Raffel, M., \& Pratt, D. M. (1997). The big ten student suicide study: A 10-year study of suicides on Midwestern university campuses. Suicide \& Life-Threatening Behavior, 27(3), 285-303.

Stallman, H. M. (2008). Prevalence of psychological distress in university students Implications for service delivery. Australian Family Physician, 3(8), 673-677.

Storrie, K., Ahern, K., \& Tuckett, A. (2010). A systematic review: Students with mental health problems--a growing problem. International Journal of Nursing Practice, 16(1), 1-6. http://dx.doi.org/10.1111/j.1440-172X.2009.01813.x

Swinton, J. (2001). Spirituality and Mental Health Care: Rediscovering a forgotten dimension. London: Jessica Kinglsey Publishers.

US Department of Education, National Center for Education Statistics. (2006). Retrieved January 30, 2012, from http://nces.ed.gov/pubs2006/2006030_1.pdf

Van Niekerk, L., Viljoen, A. J., Rischbleter, P., \& Scribante, L. (2008). Subjective experience of depressed mood among medical students at the University of Pretoria. South African Journal of Psychology, 14(1), 27-31.

Wittchen, H. U., Nelson, C. B., \& Lachner, G. (1998). Prevalence of mental disorders and psychosocial impairments in adolescence and young adults. Psychological Medicine, 28(1), 1-24. http://dx.doi.org/10.1017/S0033291797005928 